\title{
Computers and computing in psychology: Twenty years of progress and still a bright future
}

\author{
N. JOHN CASTELLAN, JR. \\ Indiana University, Bloomington, Indiana
}

\begin{abstract}
Computers and technology in psychology can be a cornucopia or a Pandora's box. During the 20 years of its existence, the Society for Computers in Psychology has been an important focus for the appropriate and beneficial application of computing technology in psychology. Although the increase of computer use is unmistakable, cyclic trends in computer applications also can be identified and, together with current technological developments, lead to predictions, concerns, and challenges for the future.
\end{abstract}

During the 20 years since this Society was founded, much has happened-and much will happen in the future. As the "middle" president of the Society, I presided over the 10th Annual Meeting in 1980. At that time, I reflected on what had happened over the preceding decade, and I was bold (or foolish) enough to make some predictions about the future (Castellan, 1981). Being a somewhat slow learner, I am about to try it again.

As the Society enters its third decade, computers are ubiquitous-not just in psychology and in our colleges and universities, but in our daily lives and society at large. Not only have computers become essential in our research laboratories, they are on our desktops and have become an integral part of instruction and learning.

In my 1980 presidential address, I argued that history might be cyclic, and that there already was evidence of cycles in computing. In preparing for that address, I reviewed all of the proceedings of the Society's meetings published in Behavior Research Methods \& Instrumentation in an effort to support my hypothesis. Two trends that I then identified, when viewed from the added perspective of the $1980 \mathrm{~s}$, reveal the cyclic patterns that I thought I had seen.

In the early 1970s, groups of faculty and departments were installing minicomputers and timesharing systems as shared resources. By 1980 , there was a distinct trend away from departmental systems to the microcomputers that were then emerging on the scene. Today, we seem to have come full circle as departments are installing local area networks to connect the large numbers of microcomputers found in our laboratories, offices, and classrooms. Connectivity has become the trend of the 1990 s.

Also in the early 1970s, there were discussions of special-purpose languages for conducting and controlling psychological experiments (Castellan, 1973). By 1980,

Requests for reprints should be addressed to N. John Castellan, Jr., Department of Psychology, Indiana University, Bloomington, IN 47405. castellan@IUBACS or castellan@UCS.INDIANA.EDU. the number of papers on that topic at the annual meeting of the Society had dropped to a trickle. But in the last 3-4 years, papers on specialized languages for psychological and behavioral research have begun to appear again. I suspect that this, again, is part of a cycle. In the early days, special-purpose languages evolved because the standard languages like BASIC and FORTRAN did not seem to meet our needs well. We needed to control events and devices. As the standard languages became better able to handle our paradigms, the necessity of special-purpose languages for experimental control became less obvious. Today, the standard languages and the needs of researchers appear to be once again out of phase. However, in the next few years, the development and deployment of object-oriented languages will mean that the standard languages may again serve us well. There is evidence of this in the papers presented by Dixon (1991) and Lesgold et al. (1990).

Communication between us has both changed and not changed. Fifteen years ago, Walter Sedelow (Sedelow, 1976) outlined how networks would change the way we work. In the next year, Phil Spelt and Karl Zinn (Spelt, 1977; Zinn, 1977) presented what then were state-of-theart techniques for computer conferencing. What they described is not much different from what we can now accomplish easily with BITNET or INTERNET, but I think that all three underestimated the extent to which we would depend on electronic communications and data highways in the 1990s.

Between 1970 and 1980, there were dramatic decreases in the cost of computers. In 10 years, the costs dropped by an order of magnitude. (See Castellan, 1981, for details.) In 1970-1971, a DEC PDP-11 system cost \$20,000. Bare systems with $2 \mathrm{~K}$ (sic) memory could be obtained for as little as $\$ 4,650$, but viable systems would cost about $\$ 12,900$; it would take another $\$ 8,000$ to bring memory up to $12 \mathrm{~K}$ (sic). In 1980 , at the end of our survey, a $16 \mathrm{~K}$ Apple could be purchased for $\$ 900$ (educational pricing), and a 16K Radio Shack TRS- 80 III could be obtained for as low as $\$ 600$. These low basic prices not withstanding, at that time a viable system would cost $\$ 2,500-\$ 3,000$. 
Today, prices appear to have continued their downward trend. A $256 \mathrm{~K}$ memory chip costs about $\$ 1.30$. The Apple Macintosh Classic has a street price of less than $\$ 1,000$. An IBM 286 compatible can be purchased for as low as $\$ 700$. But a viable system still costs about $\$ 1,500-\$ 2,500$. That is, the real entry price has not dropped very much in a decade. But wait! I have not adjusted prices for constant dollars. And more importantly, I used the "weasel" phrase "viable system." In 1970, a viable system had little memory and a BASIC language interpreter-sometimes even a multipass FORTRAN compiler. We were happy, albeit sometimes frustrated, with our systems. The same was true in 1980, but an elementary operating system and word processor would be included. Today, a viable system has a powerful operating system, sophisticated word processing and spreadsheet software, powerful programming languages (even BASIC is much different from what it was in 1970), usable graphics, and so forth, all of which require large amounts of memory and disk storage. While component prices are still dropping, system prices may have bottomed out (or nearly so), mostly because we demand more powerful systems to meet our needs.

\section{The Future As Seen From 1980}

I would like to remark briefly on the comments I made in 1980 about the future. I was excited by a presentation that year on the use of videodisk technology in research (Hooper, 1981). A decade later we are only beginning to see serious applications of videodisk (and CD-ROM) technologies in research. (Although virtually every library has at least one CD-ROM database.)

Communication. Electronic communication was seen as a positive force for the growth of science. I wondered aloud whether networks really opened doors or whether closed systems would merely become more efficient. Experience now shows that electronic communication has opened many doors. Colleges and universities have made the necessary resources available, and nationwide (and world-wide) networks are easily accessible. Informal discussion with colleagues reveals that not only do they communicate regularly with colleagues at other universities, they often get notes from students at other schools who have read about their work. The battle for open and easy access almost seems to be won. Nonetheless, some institutions are exacting a high price for communications, and not all are convinced that it has become essential to our work. Although there are fewer "have nots" in this area than there were 10 years ago, we must be vigilant to ensure that our electronic communications systems become increasingly open and accessible.

Statistics. In 1980, the primary statistical packages we used were SPSS, SAS, and BMD. A decade later, those packages are still dominant, but they have been joined by others like SYSTAT and MINITAB. I had expected greater growth in computer-intensive techniques with less restrictive assumptions-techniques such as bootstrap or permutation procedures. Inroads have been made (e.g., Stat-
Xact), but tradition still dominates our statistical analyses. Graphical techniques are more prevalent, but their infusion into our everyday work has been surprisingly slow. Perhaps the greatest change has been in the area of scaling techniques, as in LISREL.

Instruction. The use of computers in teaching and learning has become more widespread. But whereas the early emphasis was on teaching and instructional software, we have become more focused on learning and "toolbased" approaches to skill and knowledge acquisition (Butler, 1988; Castellan, 1987, 1988; Chute, 1986). To me, the lack of growth and development of instructional computing (broadly defined) and related pedagogy has been the biggest disappointment of the decade. Although there have been skirmishes here and there, the revolution envisioned in 1980 (and in 1970 also) has not taken place. Instructional computing may be the biggest and most exciting challenge of the $1990 \mathrm{~s}$, because it forms a natural and powerful union of technology and cognitive theory!

Outsiders as insiders. I concluded my presentation in 1980 with a scenario in which computers were widely dispersed outside academe. I saw this as good and suggested that "it is entirely possible that the way we view and study behavior in 1990 will owe a debt to some freckled kid playing with her microcomputer"' (Castellan, 1981). To my surprise and delight, I recently discovered that some laboratory software designed for use in undergraduate research methods courses had won awards as exemplary high school science software (Gregory \& Poffel, 1985). This prediction has turned out to have some added support-at least one high school student has won the Outstanding Student Paper Award at the annual meeting of the Society for Computers in Psychology. Finally, the high school students of the 1980s are now our graduate students, and many of them will soon join us as colleagues in research and teaching. They will change the face of psychology. At least one prediction came true.

\section{Trends}

The presentations today should give us pause. Don Tepas (1991) has raised some critical questions concerning the application of technology. Geoff Loftus (1991) asked his question about whether using the computer is leading to better or simply more research. Others have raised similar questions. But has there been fundamental research on these questions? Any failure to address such questions risks damage to the science we espouse.

Since I do not know the answers to these important questions, I will turn briefly to some trends that are worth watching. Not only should we be interested in these developments in technology for what they can do to assist us in our professional work, we should also think about them as aspects of behavior worthy of serious study and analysis.

Workstations. Workstations like Suns and Apollos have made significant inroads into the scientific community. They have tremendous potential to change the face 
of psychology. Graphical spreadsheets like WingZ enable us to grasp complex relations in our data easily. Realtime processing of complex data is becoming a reality. Tools like Mathematica can help us solve complex problems rapidly and in a manner that more closely matches the problem-solving approaches we would prefer to use. Software is readily available that can let any researcher or student explore computer modeling techniques, such as parallel distributed processing (PDP) or connectionist models (McClelland \& Rumelhart, 1988).

Scientific visualization. Powerful graphics and animation systems are enabling scientists to view the products of thought in ways not possible with earlier technology. These systems should enable scientists to better understand complex phenomena-particularly dynamic systems. Not only can we visualize physical systems, we can come to better understanding of sensory and physiological processes through realistic simulation.

\section{Summary}

The 1970s and 1980s were decades of rapid change in the utility of computing technology. The resources at our fingertips stretched our imagination and led us to think in new and creative ways. Although I do not have time to outline it in detail, I would like to propose a final thesis: In the 1960 s and 1970 s, psychologists quickly comprehended the potential of computers. The state of the art was such that researchers' needs were at or beyond the cutting edge of the technology. The latest developments were infused rapidly into the laboratory. During the 1980 s, it seems that, in general, computing technology began to advance faster than our research methodologies. Researchers found it increasingly easy to find resources to meet their needs. In the 1990 s, computing technology will continue to advance faster than advances in methodology. If this assumption is true, it will become even cheaper and easier to establish effective and productive laboratories. Moreover, if this phenomenon extends beyond laboratories, it also poses a challenge articulated in Alan Lesgold's (1991) comments today: How will our methodologies advance to match the technological possibilities for examining and understanding complex behavior?

Computers and technology in psychology can be a cornucopia or a Pandora's box. As my fellow past presidents of this Society Don Tepas (1991), Alan Lesgold (1991), and Geoff Loftus (1991) correctly argue in their presentations, computers can be empowering-or they can enslave. It is our responsibility as users to choose.

\section{REFERENCES}

BUTLER, D. L. (1988). Selection of software in the instructional laboratory. Behavior Research Methods, Instruments, \& Computers, 20. 175-177.

CASTELlAN, N. J., JR. (1973). Laboratory programming languages and standardization. Behavior Research Methods \& Instrumentation, 5, 249-252.

Castellan, N. J., JR. (1981). On-line computers in psychology: The last 10 years, the next 10 years-The challenge and the promise. Behavior Research Methods \& Instrumentation, 13, 91-96.

Castellan, N. J., JR. (1987). Computers and the shape of the future: Implications for teaching and learning. Education \& Computing, 3, 39-48.

Castellan, N. J., Jr. (1988). Comments on applications of microcomputers in teaching. Behavior Research Methods, Instruments, \& Computers, 20, 193-196.

Chute, D. L. (1986). MacLaboratory for psychology: General experimental psychology with Appie's Macintosh. Behavior Research Methods, Instruments, \& Computers, 18, 205-209.

Dixon, P. (1991). The promise of object-oriented programming. Behavior Research Methods, Instruments, \& Computers, 23, 134-141.

Gregory, R. J., \& Poffel, S. A. (1985). START: Stimulus and response tools for experiments in memory, learning, cognition, and perception. Iowa City, IA: Conduit, University of lowa.

HOOPER, K. (1981). The use of computer-controlled video disks in the study of spatial learning. Behavior Research Methods \& Instrumentation, 13, 77-84.

LESGOLD, A. (1991). Research methodology in the postinformatic age. Behavior Research Methods, Instruments, \& Computers, 23, 109-111.

Lesgold, A., Hughes, E., Burnzo, M., McGinnis, T., Gordin, M., RAO, G., Prabowo, R. (1990, November). Tools for developing interactive software for research and education. Paper presented at the annual meeting of the Society for Computers in Psychology, New Orleans, LA.

Loftus, G. R. (1991). Postdictions of 20-year predictions about the state of computer technology in psychology (and one or two other matters). Behavior Research Methods, Instruments, \& Computers, 23, 112-113.

McClelland, J. L., \& Rumelhart, D. E. (1988). A simulation-based tutorial system for exploring parallel distributed processing. Behavior Research Methods, Instruments, \& Computers, 20, 263-275.

SEDELOW, W. A., JR. (1976). Some implications of computer networks for psychology. Behavior Research Methods \& Instrumentation, 8, 218-222.

SPELT, P. F. (1977). Evaluation of a continuing computer conference on simulation. Behavior Research Methods \& Instrumentation, 9, 87-91.

TEPAS, D. I. (1991). Computers, psychology and work: Does the past predict a troubled future for this union? Behavior Research Methods, Instruments, \& Computers, 23, 101-105.

ZINN, K. L. (1977). Computer facilitation of communication within professional communities. Behavior Research Methods \& Instrumentation, 9, 96-107. 